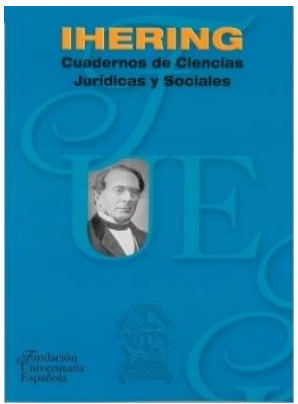

(c) $($ i) (9)
Ihering. Cuadernos de Ciencias Jurídicas y Sociales N. 4

Año: 2021

Publicación del SEMINARIO DE ESTUDIOS EUROPEOS "DIEGO DE MENDOZA" de la

Fundación Universitaria Española

e-ISSN: 2660-552X

DOI: https://doi.org/10.51743/ihering.284

Recibido: 24-10-2021 | Revisado: 20-11-2021

|Aceptado: 15-12-2021 | Publicado: 23-12-2021

\title{
LA REAL SOCIEDAD ECONÓMICA MATRITENSE BAJO LA REGENCIA DE MARÍA CRISTINA DE BORBÓN: EL FOMENTO DE LA MODERNIZACIÓN LOCAL
}

\author{
THE REAL SOCIEDAD ECONÓMICA MATRITENSE UNDER THE \\ REGENCY OF MARÍA CRISTINA DE BORBÓN: THE PROMOTION OF \\ LOCAL MODERNIZATION
}

\author{
Ricardo Colmenero Martínez \\ $\underline{\text { Universidad de Alcalá }}$
}

\section{Resumen}

Este artículo forma parte de mi aportación al Grupo de Investigación Historia Política de la España contemporánea de la Universidad de Alcalá, clasificado como Grupo de Alto Rendimiento por resolución de la Comisión de Investigación de 23 de octubre de 2019, ratificada por Consejo de Gobierno de la UAH de 31 de octubre. 
Palabras clave: Las Reales Sociedades Económicas de Amigos del País, Real Sociedad Económica Matritense de Amigos del País, María Cristina.

\begin{abstract}
This article is part of my contribution to the Political History of Contemporary Spain Research Group at the University of Alcalá, classified as a High Performance Group by resolution of the Research Commission of October 23, 2019, ratified by the Governing Council of the UAH as of October 31.
\end{abstract}

Key words: The Royal Economic Societies of Friends of the Country, Royal Matritense Economic Society of Friends of the Country, María Cristina.

\title{
1. EL INICIO DEL “ILUSTRADO” REINADO DE ISABEL II
}

Las Reales Sociedades Económica de Amigos del País han conocido, a lo largo de los últimos siglos, varios periodos de impulso y decadencia ${ }^{202}$. Nacidas en el reinado de Carlos III, inicialmente fueron apoyadas por las elites ilustradas, a nivel provincial y central, aunque fueron poco a poco mermando su labor, sobre todo por falta de medios económicos sólidos. Conocieron un segundo impulso durante los primeros años del gobierno de Manuel Godoy, hasta que de nuevo se aletargaron al final del reinado de

${ }^{202}$ Este artículo forma parte de mi aportación al Grupo de Investigación Historia Política de la España contemporánea de la Universidad de Alcalá, clasificado como Grupo de Alto Rendimiento por resolución de la Comisión de Investigación de 23 de octubre de 2019, ratificada por Consejo de Gobierno de la UAH de 31 de octubre.

Ihering. Cuadernos de Ciencias Jurídicas y Sociales N ․ㅡ 4 (2021)

DOI: https://doi.org/10.51743/ihering.284 
Carlos IV. Tras la guerra de la Independencia, los primeros gabinetes de Fernando VII aceptaron su restablecimiento, sobre todo por su carácter moderado y reformista, pero al adscribirse muchos de sus miembros al constitucionalismo durante los años del Trienio Liberal (1820-1823), nuevamente las Sociedades Económicas cayeron en el aturdimiento ${ }^{203}$. Pero, tras la muerte del rey, se abrió una nueva fase política favorable al reformismo durante la regencia de María Cristina de Borbón (1833-1840). La propaganda oficial divulgó, en la sociedad española, la idea de que comenzaba el "ilustrado reinado de Isabel II", por lo que el gobierno se mostró a favor de la restauración e impulso de las Económicas.

En diversos boletines provinciales se anunció el decreto que favoreció la resurrección de los Amigos del País. En un preámbulo realizado con un lenguaje tardoilustrado, se animó a las provincias a constituir Sociedades y Ateneos donde se canalizará el espíritu de asociación, que la regente permitía, siempre con la finalidad de la búsqueda del progreso nacional. Este llamamiento debe entroncarse en el conjunto de gestos que María Cristina y sus colaboradores políticos realizaron para lograr el mayor apoyo posible de las elites regionales frente al peligro del carlismo, afianzando las bases sociales del trono de Isabel II. Como también el ministerio de Fomento deseaba un mayor control de estas entidades, se

203 Antonio Manuel MORAL RONCAL y Ricardo COLMENERO MARTínEZ, "Un espacio reformista en el Madrid de Fernando VII: la Real Sociedad Económica Matritense de Amigos del País (1814-1833)", Madrid: Revista de arte, geografía e historia, 8 (2006) pp. 87-127. 
dispuso que sus subdelegados en provincias fueran su nexo de comunicación. Siguiendo el ideal de administración centralizada napoleónica, la administración depositó sus esperanzas en que estas instituciones se convirtieran en cauces de información y de planes de fomento de la economía. En 1834 la llamada obtuvo como resultado la reinstalación de veinticinco Sociedades Económicas, que también nombraron representantes de estas en la asentada en la capital, los cuales funcionaron como diputación permanente ${ }^{204}$.

El 2 de abril de 1835 se aprobaron nuevos estatutos para las Económicas, por lo cual, siete días más tarde, la reina ordenó que se celebrara una junta general en todas las Económicas, para elegir una comisión que acordara las medidas necesarias para lograr su cumplimiento entre sus socios. Asimismo, se dictaminó que aquellas que todavía no se hubieran dividido internamente en clases o secciones especializadas de trabajo lo hicieran, que se organizaran las elecciones para cargos directivos y juntas para el nombramiento de nuevos socios, impulsando de esta manera su renovación. Además, para evitar gastos, María Cristina sufragó, a cargo de la administración de correos de cada provincia donde había una

${ }^{204}$ Archivo de la Real Sociedad Económica Matritense (ARSEM), Libro de Actas A/110/45. Sobre instalación y nombramiento de diputaciones permanentes en la Villa y Corte, ver leg. 314, exp. 3 y leg. 320, exp. 9.

Ihering. Cuadernos de Ciencias Jurídicas y Sociales N ․ㅡ 4 (2021)

DOI: https://doi.org/10.51743/ihering.284 
Sociedad, la reimpresión de los estatutos y su distribución gratuita entre los socios 205 .

Al año siguiente, varias sociedades elevaron una serie de sugerencias a la reina, solicitando la modificación de algunos de los artículos de los estatutos aprobados el pasado 2 de abril. Los Amigos del País no deseaban ninguna intervención ni influencia directa del gobierno, pues, al querer ayudarlas, las entorpecería en su labor por lo que solicitaron ser cuerpos libres interesados en el bien público con asociación ilimitada, para poder subsistir por puro patriotismo. Una vez consultada una comisión jurídica, María Cristina aceptó alguna modificación, pero con condiciones: las Sociedades podían modificar los estatutos libremente, pasando una copia de las nuevas al gobernador civil. Pero si aceptaban fondos públicos para su funcionamiento, debían pasar a aprobación de la reina y el gobernador civil presidiría la corporación para asegurar una buena administración de ese dinero. Además, ninguna Sociedad podría dirigir establecimiento alguno, costeado con fondos públicos, si no era por comisión del gobernador civil de acuerdo con la diputación provincial ${ }^{206}$.

${ }^{205}$ Real Orden de 9 de abril de 1835 publicada en La Gaceta de Madrid, № 124, 4 de mayo de 1835, p. 1.

${ }^{206}$ Salvo cuatro artículos, el resto de los establecidos en el decreto de 2 de abril, debían ser respetados por aquellas Sociedades que, por las circunstancias arriba descritas, debían someter sus estatutos a la firma regia. Real Orden de 14 de febrero de 1836, publicada en La Gaceta de Madrid, nㄴ26, 21 de febrero de 1836, p. 3.

Attribution-NonCommercial 4.0 International (CC BY-NC 4.0). e-ISSN: 2660-552X 
La Sociedad de la capital había sobrevivido difícilmente y, vista la experiencia anterior, se negó a transformarse en una institución de carácter político, en un foro de luchas partidistas violentas entre liberales moderados y exaltados, entre conservadores y reformistas. Además, el telón de fondo de la regencia lo constituyó la Primera Guerra Carlista, que tardó siete años en ser extinguida. Por todo ello, la Matritense -y por su influencia el resto de las Sociedades -favoreció la convivencia de los diferentes grupos políticos que fueron surgiendo durante esa década en la España isabelina, no faltando la presencia, incluso, de elementos conservadores, pero tardoilustrados. La expulsión o no elección de algunos socios nunca provino de los Amigos del País, sino de los cambios constantes en que se vio envuelto el escenario político a nivel local.

La Matritense dependió, durante buena parte de su historia, de las ayudas económicas de la Corona o del gobierno, por lo que los socios evitaron la crítica política, mostrándose continuamente a favor de la colaboración con las autoridades tanto a nivel estatal como municipal. Nunca fue una logia masónica ni sede de un partido, aunque algunos de sus 200 socios aceptaran su ingreso en esas corporaciones. El Estado liberal en construcción, que deseaba diseñar una sociabilidad controlada y controlable, al tiempo que trataba de modernizar la nación, apoyó finalmente a las Económicas, que trataron de reimpulsar su presencia y labor en todo el reino durante esta época. 
Como, además de la tolerancia del poder político, la Matritense necesitaba una financiación regular, su directiva impulsó una asociación amplia y unas buenas relaciones con administración cristina para poder aumentar, de esa manera, los fondos de su tesorería. Todavía no tenía una sede propia, por lo que se los Amigos del País se reunieron en las casas del Ayuntamiento o en el Real Colegio de Sordomudos, hasta que en 1866 el gobierno les cedió la Torre de los Lujanes, junto a la Real Academia de Ciencias Política y Morales.

\section{UN LIDERAZGO DECISIVO}

Indudablemente, tuvo su importancia el hecho de que sus directores fueran personas con cierta capacidad de influencia política, a nivel local, o de prestigio entre las altas esferas del reformismo.

El primer director de la Matritense, bajo la regencia, fue Juan Álvarez Guerra (1770-1845), consejero de Estado y miembro del Estamento de Próceres, fue director general de Correos y ministro de Gobernación. Su nombre se encontraba ligado a las guerrillas de la guerra de la Independencia y al desarrollo de la taquigrafía, ya que fue autor en 1800 de una traducción al castellano del sistema de Samuel Taylor, profesor de Oxford, siendo la segunda obra de esta materia que apareció en España. Ingresó en la Matritense el 3 de noviembre de 1794, siendo elegido director en 1834 y 1842. Idéntico puesto ocupó en la diputación permanente en Madrid de la Sociedad Económica de Cáceres, bajo la 
regencia de Espartero ${ }^{207}$. Como veremos, impulsó la creación del Ateneo de Madrid y puso sus redes de contactos políticos al servicio de la Matritense.

Le sucedió su subdirector, Antonio Sandalio de Arias Costa (17741839), catedrático de Botánica de reconocido prestigio. A finales de 1833, se promulgaron las Ordenanzas Generales de Montes, estableciéndose una Dirección y una Inspección General de Montes, cargos que recayeron en Manuel Pérez Seoane y Arias equitativamente. María Cristina nombró a Arias inspector general de Montes, y el 25 de julio de 1834 fue nombrado comisario interino hasta septiembre de 1837 en que desapareció definitivamente la Junta de Protección y con ella el cargo de comisario del Real Jardín Botánico. Arias acometió en 1835 otros proyectos e iniciativas reformistas en política forestal, que no fructificaron por los continuos cambios de gobierno y el fallecimiento de Arias cuatro años después. Impulsó la creación del Cuerpo de Ingenieros Civiles, que contó entre sus Inspecciones con las de Ingenieros Geógrafos y de Bosques. Además, se creó en Madrid la Escuela Especial de Ingenieros de Bosques bajo su dirección y para la que había redactado un reglamento dos años antes. Se le propuso como director facultativo de Arbolados, pero en deferencia hacia su colega, Francisco Sangüesa, renunció en su favor.

207 José Luis GARCíA BROCARA, La Sociedad Económica Matritense de Amigos del País. Páginas de una gloriosa historia, Madrid, Artes gráficas Reyes, 1976, p. 69. 
Su trayectoria científica y profesional fue reconocida por las sociedades científicas nacionales e internacionales a las que perteneció, con las que colaboró en comisiones y misiones relevantes. Fue, junto a un profuso conjunto de intelectuales y profesores, socio fundador de la Academia de Ciencias Naturales que se instituyó en la capital en 1834 y en cuya solicitud inicial Arias figuró encabezando la instancia presentada al efecto. Al año siguiente, Arias ocupó la subdirección de la Sociedad Económica Matritense y desde 1836 hasta 1839 la dirección de la misma. Fue secretario honorario de la reina y uno de los directores de la Dirección General de Estudios. La Sociedad Económica Matritense reconoció sus servicios y costeó la lápida del sepulcro y colocó su retrato en su sala de sesiones $^{208}$.

Miembro también de esa elite favorable a aprovechar los tiempos de la regencia para modernizar la ciudad de Madrid, fue elegido Joaquín Vizcaíno Martínez (1790-1840) XXIII director de la Matritense el 23 de diciembre de 1837. Su currículum liberal estaba blasonado con su grado de comandante de la milicia nacional y por su estancia en el exilio tras el final del trienio constitucional. Viudo de la marquesa de Pontejos, fue corregidor y jefe político de la capital, senador, fundador y primer director de la Caja de Ahorros, entidad que ayudó a fundar. En la Económica presentó memorias y disertaciones sobre los premios al ganado de tiro texto impreso en el Semanario Pintoresco-, la navegación en los ríos, la

${ }^{208}$ GARCÍA BROCARA, La Sociedad Económica..., pp. 70 y ss. 
policía urbana, los balnearios y las sociedades médicas. Entre sus trabajos destacó su propuesta para establecer un gabinete de productos provinciales y una empresa general de obras de utilidad pública; un informe sobre la fabricación de tejas holandesas, una memoria sobre las tareas de la Matritense, un informe sobre la industria popular y el impulso a los premios agropecuarios, una propuesta sobre la fundación de asociaciones de socorros mutuos para caso de enfermedad. Su fama de filántropo preocupado por la cuestión social fue muy importante, falleciendo rodeado de un respeto de la ciudadanía ${ }^{209}$.

En 1839 asumió la dirección Eusebio María del Valle, marqués del Valle Santoro (1799-1867). Licenciado en leyes, doctor en jurisprudencia, ejerció como catedrático de Derecho Natural en los estudios de San Fulgencio hasta el final del trienio liberal. Decidió estudiar ciencias naturales y economía política, asumiendo la cátedra de esta última materia en la Matritense y, más adelante, en la Universidad Central, primero en la Escuela Especial de Jurisprudencia y luego en la Facultad de Filosofía, de la

\footnotetext{
${ }^{209}$ Sobre este liberal me remito a VIVES, J. L., "El corregidor marqués viudo de Pontejos", Torre de los Lujanes, 20 (1992), pp. 121-127; SALVADOR PRIETO, María del Socorro, "Precisiones sobre la erección de las estatuas del padre Piquer y el marqués de Pontejos en Madrid", Archivo español de Arte, 62 oo 247 (1989) pp. 360-363; Joaquín MARTín MUÑOZ, "La gestión del marqués viudo de Pontejos en el Ayuntamiento de Madrid" en Luis E. OTERO y Ángel Bahamonde (eds.), Madrid en el siglo XIX, Madrid, Comunidad de Madrid, 1986, pp. 193-209; Id., La política local en el Madrid de Pontejos (1834-1836), Madrid, Caja de Madrid, 1995.
}

Ihering. Cuadernos de Ciencias Jurídicas y Sociales N.ำ (2021)

DOI: https://doi.org/10.51743/ihering.284 
que cual llegó a ser decano ${ }^{210}$. Ingresó en la misma en 1833 y antes de ser director, ejerció los cargos de censor y subdirector.

\section{SOCORRE ENSEÑANDO}

Ya en sus primeros estatutos, la Matritense estableció en su título 10, artículo 20 que "la empresa o sello de la Sociedad representa simbólicamente la agricultura, las artes y el comercio con el lema o membrete Socorre enseñando". Pronto una comisión de socios fue encargada de diseñar el emblema de acuerdo con los estatutos que fue grabado, consistió en un círculo en cuya área aparecieron un conjunto de útiles formando un haz, sujeto por una cinta que pendía de la parte superior del emblema. Formaban este haz unas tijeras, un compás, un martillo, una lima, unas tenazas, un hacha y un tiralíneas; en la base, a un lado del arado y al otro un banco de hilar, con torno y rueca. Dentro del círculo en su parte superior una cinta con el famoso lema de la Sociedad. El círculo fue rodeado de una guirnalda de hojas de roble envuelva en una cinta y rodeada de cuatro ramos, dos de laurel y dos de palma. Aunque este diseño sufrió alguna variación con el paso del tiempo, fue considerado

${ }^{210}$ Valle influyó en economistas liberales agrupados en la escuela economista, como Manuel Colmeiro y Laureano Figuerola, con los cuales compartió labores docentes y en los primeros krausistas, por ejemplo, sus dos discípulos Ruperto Navarro y José Álvaro de Zafra. Con ellos editó la Revista Económica de Madrid. Luis PERDICES, "Valle, Eusebio María del", en Luis PERDICES y John REEDER (eds.), Diccionario de pensamiento económico en España 1500-2000, Madrid, Síntesis-ICO, 2003, p. 412.

Attribution-NonCommercial 4.0 International (CC BY-NC 4.0). e-ISSN: 2660-552X 
definitivo ${ }^{211}$. En los impresos de 1821 apareció sin los adornos vegetales exteriores, pero volvió a registrarse completo entre 1830 y 1863.

La Matritense, siguiendo la estela creada hasta el momento, continuó su labor de fomento de la educación, tanto general como especializada, en su ámbito geográfico de actuación ${ }^{212}$. Otorgó premios a los mejores maestros, maestras y alumnos de las escuelas y hospicio de la capital, incluso en el aprendizaje y docencia de materias como latinidad, poética y retórica. Así como se concedía a los varones un título de socio de mérito, a las maestras se les ofertó premios en metálico, quizá para remediar la situación en la que se encontraban muchas de ellas, rozando la indigencia ${ }^{213}$. Por otra parte, los Amigos del País procuraron apoyar diversas iniciativas educativas.

A comienzos de siglo, habían patrocinado la enseñanza de la taquigrafía, abriendo una escuela pública, para lo cual se había destinado la parte baja de edificio que fue almacén de cristales de La Granja, en la calle del Turco, actualmente denominada del marqués de Cubas. La escuela

${ }^{211}$ Carlos GONZÁLEZ ECHEGARAY, "Reseña histórica de los emblemas de la Sociedad Matritense", Torre de los Lujanes, 31 (1996) pp. 257-258.

212 El fomento de la enseñanza a nivel local fue empresa común de todas las Económicas, incluso en zonas tal alejadas como la isla de Cuba. Allí, bajo la regencia de María Cristina, la de la Habana sostuvo una escuela de música, una academia de pintura, escultura y dibujo y fomentó la enseñanza de la botánica y la química en otro establecimiento, como analiza Daisy RIVERO, "La Sociedad Económica de Amigos del País de la Habana: nacionalidad y nación", Torre de los Lujanes, 33 (1997), p. 177.

${ }^{213}$ La Gaceta de Madrid, no 235, 7 de octubre de 1834, pp. 987 a 988. 
funcionó regularmente hasta la invasión francesa, tras lo cual se interrumpieron las lecciones. Retiradas las tropas napoleónicas de la capital, se abrió de nuevo en mayo de 1813, de la mano del socio y primer catedrático Francisco de Paula Martí. Ya en los años de la regencia de María Cristina, dirigía el establecimiento su yerno y discípulo Sebastián Eugenio Vela, que continuó enseñando con los manuales de su suegro, Taquigrafía castellana y Taquigrafía de la música. Todos los taquígrafos que sirvieron en las Cortes, desde las gaditanas de 1810 hasta las del Estatuto Real, pasando por las del Trienio Liberal (1820-1823) se formaron en esta cátedra. Trabajaron no sólo en las sesiones parlamentarias sino en la elaboración del propio diario de las Cortes. Asimismo, uno de sus alumnos, Francisco Serra y Gineta, abrió su propia escuela en Barcelona, sobre todo para jóvenes ligados al comercio y la administración.

A finales de los años treinta, la sección de Contabilidad y Depositaría de la Dirección General de Estudios compartía también el edificio de la calle del Turco con la escuela. Este organismo oficial propuso, ante la necesidad de ampliar sus oficinas, que la Real Sociedad Económica cediese una sala interior del piso principal junto con la de la cátedra de Taquigrafía, a cambio de un local para la misma en el edificio de los Estudios de San Isidro. La Matritense aceptó el cambio, trasladándose las clases al edificio de San Isidro en la calle de Toledo ${ }^{214}$.

214 José Luis GARCÍA BROCARA, "La reinstalación de la escuela de taquigrafía en el Instituto de San Isidro", Torre de los Lujanes, 24 (1993) pp. 189-197.

Attribution-NonCommercial 4.0 International (CC BY-NC 4.0). e-ISSN: 2660-552X 
Asimismo, la Matritense seguía protegiendo el Colegio de Sordomudos, situado también en la calle del Turco. En 1802 había solicitado a la Corona el establecimiento de esta escuela en Madrid dotada con fondos provenientes de algunas mitras del sur. Abierto dos años más tarde, se tuvo que cerrar durante la guerra de la Independencia, pero se restableció con la paz, siendo dirigida por los Amigos del País hasta 1822 en que pasó a la Dirección General de Estudios. Al año siguiente, el rey le señaló una serie de arbitrios sobre fundaciones religiosas, rentas de correos y el propio Diario de Madrid, para su sostenimiento, bajo la dirección del duque de Híjar. En 1835, la Matritense volvió a encargarse de nuevo de este establecimiento, mejorando su enseñanza, estableciendo una serie de talleres de imprenta y librería en los que se ocupaban colegiales sordomudos, pues se necesitaban dos cajistas, seis prensistas y un encuadernador ${ }^{215}$. Sus encargos y trabajos fueron aumentando, así como el número de plazas de tal manera que, en 1846, convivían veintinueve internos inclusos, cuatro pensionistas y diecisiete externos, de los cuales nueve eran mujeres. La inspección de la Matritense también organizó una serie de concursos de premios anuales para los alumnos y profesores más adelantados.

Junto a este colegio se estableció también una enseñanza dirigida a los ciegos, al desestimarse el Hospicio. Juan Manuel Ballesteros, socio y

215 Eduardo MONTAGUT CONTRERAS, "La creación de la imprenta del Colegio de Sordomudos de Madrid”, Torre de los Lujanes, 27 (1994), pp. 273-288.

Ihering. Cuadernos de Ciencias Jurídicas y Sociales N.ำ 4 (2021)

DOI: https://doi.org/10.51743/ihering.284 
maestro de sordomudos, hizo una serie de ensayos con algunos de ellos, antes de presentar un proyecto a la Económica Matritense el 13 de julio de 1834, la cual apoyó sin fisuras la idea en beneficio de personas vulnerables. El 11 de septiembre de 1835 abrió la escuela para alumnos externos de ambos sexos, desde los siete años, dividiendo las mañanas en la docencia a niños y las tardes para las niñas ${ }^{216}$. De nuevo, elevó una petición de ayuda al gobierno, el cual presentó algún reparo, pero por Real Orden de 10 de enero de 1836 se mandó a la Sociedad que elaborara un proyecto definido para una escuela interina. El día 25 de ese mes, los Amigos del País lo enviaron y fue aprobado por la regente, señalando sobre el presupuesto de instrucción pública la cantidad anual de 26.000 reales para su sostenimiento. Los alumnos educados desde 1834 hasta 1848 fueron cuarenta y cinco hombres y cuarenta mujeres. La enseñanza abarcaba no solo materias profesionales, para proporcionarles una salida laboral, como punto, aguja y telar, adorno y música, sino que -a través de libros y números en relieve- aprendieron escritura, lectura, aritmética, geografía, moral y otras asignaturas. Los libros fueron impresos por el propio establecimiento.

Como consecuencia de la desamortización emprendida por los progresistas, a partir de 1836, y de todo el proceso legal unido a ella, fue necesario leer documentos muy antiguos, notándose la falta de especialistas en paleografía y diplomática. El Estado liberal comenzó a

${ }^{216}$ La Gaceta de Madrid, o 260, 14 de septiembre de 1835, p. 1036.

Attribution-NonCommercial 4.0 International (CC BY-NC 4.0). e-ISSN: 2660-552X 
incautarse de bibliotecas y archivos eclesiásticos, incluso de órdenes militares. Una Real Orden de 2 de febrero de 1836 autorizó a la Biblioteca Nacional, a la Real Academia de la Historia y a la de Bellas Artes de San Femando a recoger los libros de los monasterios y conventos desamortizados. Junto a ellos también se acumularon determinados documentos fechados en la edad media y en la época moderna. Nuevas disposiciones desamortizadoras siguieron en corto espacio de tiempo a las anteriores. La ley de 29 de julio de 1837 declaró extinguidos, con alguna excepción, en la península, islas adyacentes y posesiones de España en África, todos los monasterios, conventos, colegios, congregaciones y demás casas de religiosos de ambos sexos. Se recogió en su articulado alguna disposición referida al patrimonio documental. En 1841, se declararon bienes nacionales aquellas propiedades, derechos y acciones de cualquier modo correspondientes a las fábricas de las iglesias y a las cofradías. La aplicación de este artículo trajo como consecuencia que la documentación de las cofradías (libros de cuentas, visitas, censos, títulos de propiedad...) y de las iglesias (libros de fábrica, censos, apeos...) pasarán a incrementar la masa documental incautada ${ }^{217}$. Todo este proceso impulsó a la Matritense, por impulso de su socio Francisco López Olavarrieta, a crear una Escuela Española de Paleografía y Diplomática.

${ }^{217}$ Antonio CABALLERO GARCÍA, “Desamortización y patrimonio documental: un ejemplo de tratamiento de archivos en el siglo XIX", Signo. Revista de Historia de la Cultura Escrita, 15 (2005) pp. 77-117.

Ihering. Cuadernos de Ciencias Jurídicas y Sociales N.ำ 4 (2021)

DOI: https://doi.org/10.51743/ihering.284 
En el colegio de Sordomudos se celebró la apertura de este establecimiento con la mayor solemnidad posible, el 20 de enero de 1839, con un discurso del profesor José de Santos y Mateos ${ }^{218}$. La Matritense comunicó al gobierno este hecho, solicitando una gratificación para el catedrático, que iba a dirigir las clases que serían gratuitas. Todo un gesto que delataba un intento de conseguir la complicidad del poder político, el cual respondió afirmativamente. Si bien fueron muchos los alumnos que se inscribieron terminaron el curso 47 matriculados, entre ellos el vicedirector de la Escuela Normal, el cual transmitió en su centro los conocimientos adquiridos.

Sobre este primer curso, director de la Matritense, el marqués viudo de Pontejos escribió su opinión en su "Memoria sobre el espíritu y tendencia de las tareas de tan útil corporación durante el año 1839",

218 José de Santos y Mateos realizó su bachiller en filosofía, cursando teología (durante cinco años), lengua hebrea (durante dos) y estudiando exposición de la Sagrada Escritura. Se convirtió en el segundo de los cinco académicos profesores de número; examinador de preceptores de Latinidad y Bellas Letras de la Academia Grecolatina, en la que desempeñó los empleos académicos con la producción de gran número de informes y trabajos literarios. Fue el encargado de la configuración de la gramática, diccionario y colección de alfabetos latinos; secretario de la comisión permanente de lengua latina, fue nombrado para la primera cátedra de dicha lengua. Realizó censuras de obras de literatura y desempeñó el cargo de académico de número de la de Ciencias Eclesiásticas de San Isidoro. El profesor Santos sacó a la luz algunas traducciones del francés, siendo versado en antigüedades hebraicas, griegas, latinas y patrias, historia, cronología, geografía, literatura, bibliografía y demás ramos de la arqueología con título de revisor y lector de letras y documentos antiguos latinos y castellanos, habiéndose dedicado desde muy joven a la paleografía en la dirección de archivos particulares. María del Val GONZÁLEZ DE LA PEÑA, "La enseñanza de la paleografía en España. Los orígenes y las primeras cátedras", en Joaquín GÓMEZ PANTOJA, Excavando papeles. Indagaciones arqueológicas en los archivos españoles, Guadalajara, Aaché Ediciones, 2004, pp. 43-71.

Attribution-NonCommercial 4.0 International (CC BY-NC 4.0). e-ISSN: 2660-552X 
expresándose en estos términos: "En este año se ha promovido y planteado la Sociedad una enseñanza poco conocida en España en la actualidad y sumamente útil como es la de la paleografía. A ella han acudido personas a quienes interesaba instruirse en este ramo y se han iniciado en él con gran provecho, pero aun cuando así fuese, la Sociedad, promoviendo esta enseñanza ha tenido ocasión de hacer una cosa ventajosa al bien general, y es la de conocer toda la instrucción y laboriosidad del digno profesor don José Santos y Mateos"219.

El gobierno dispuso por Reales Órdenes de 31 de diciembre de 1839 y 29 del mismo mes de 1840 que se atendiese a la conservación de esta escuela con fondos provenientes de la sección de imprevistos del Ministerio de la Gobernación, sobre todo para el pago de sueldos. El 4 de diciembre de 1841, la cátedra de paleografía y diplomática fue agregada al instituto de segunda enseñanza de la Universidad Central, con dotación fija para el catedrático ya incluida en los presupuestos de instrucción pública. Sin embargo, al estar el nuevo centro alejado y las horas intempestivas que se adjudicaron a sus clases, el número de matriculados disminuyó y se cerró la matricula. Santos Mateos protestó a las autoridades proponiendo un cambio de lugar y, ante la negativa, el rector de la Universidad Literaria creyó conveniente el establecimiento de la cátedra de paleografía, de nuevo, en la Real Sociedad Económica Matritense retribuyendo al profesor

${ }^{219}$ La Gaceta de Madrid, 14 de febrero de 1840, p. 4.

Ihering. Cuadernos de Ciencias Jurídicas y Sociales N.․ 4 (2021)

DOI: https://doi.org/10.51743/ihering.284 
de los fondos de "imprevistos" del Ministerio y haciéndose obligatoria dicha asignatura para aquellos que deseasen dedicarse a carrera de escribano. Poco después, el 29 de agosto de 1844, se solicitó desde instancias del mismo Ministerio que no se llevase a efecto la supresión de la cátedra.

Sin embargo, altos funcionarios exigieron informes sobre los resultados de la enseñanza de la paleografía. El director de la Matritense, de la misma manera, continuó remitiendo informes, aunque le pareció inútil insistir en la conveniencia y necesidad de estas disciplinas. Prefirió argumentar que esta enseñanza aun siendo útil a todas las clases de la sociedad, resultaba absolutamente precisa para bibliotecarios, historiadores, archiveros, escribanos y revisores de letras. Tenemos que pensar que en ese momento era escandalosa la facilidad con que los escribanos de la época daban fe de hallarse conforme la copia que suscribían con un original que ni entendían, ni sabían, ni podían leer, y ni siquiera advertir si se contenía en el documento algún vicio o falsedad del que se debiera hacer expresión. Por eso, creyó el director de la Real Sociedad Económica pertinente que a aquellos que se dedicaran a la profesión de escribanos también se les obligase al estudio de un año o dos de paleografía. Tras el dictamen de la Matritense, se restableció la cátedra, a la que se dotó con 8.000 reales anuales, bajo la inspección de una comisión de tres Amigos del País. La matrícula aumentó y la corporación 
continuó apoyando el proyecto al organizar una serie de premios a los mejores alumnos 220 .

El marqués de Pontejos propuso en la Matritense, el 10 de marzo de 1838, la creación de la Sociedad para Propagar y Mejorar la Educación Pueblo, que cuajó en el siguiente mes de julio con él como vicepresidente. La idea central consistía en aunar todas las iniciativas privadas posibles para fomentar la educación primaria, evitando el analfabetismo, aumentando la ilustración popular, siendo una reacción y una acción contra la expansión de ideales radicales. Fue creada a imitación de las iniciativas llevadas a cabo en otros reinos europeos, especialmente en Inglaterra donde los liberales exiliados habían admirado el vigoroso movimiento en pro de la educación popular impulsado por whigs y radicales bajo el liderazgo de lord Henry Brougham. Este grupo de liberales filantrópicos fomentó distintas formas de educación popular generalmente por medio de sociedades: las escuelas lancasterianas (British and Eoreign School Society), las escuelas de párvulos (The Infant School Society) y la publicación de libros baratos (Society for dic Dilfusion of Useful

220 Pascual MADOZ, Madrid. Audiencia, provincia, intendencia, vicaría, partido y villa (1848). Reedición, Madrid: Ediciones Giner, 1981, p. 307.

Ihering. Cuadernos de Ciencias Jurídicas y Sociales N. 04 (2021)

DOI: https://doi.org/10.51743/ihering.284 
Knowledge). Pontejos había estudiado en Francia y Gran Bretaña, durante su exilio, estas iniciativas y las trasladó a Madrid 221.

El gobierno apoyó la iniciativa y encargó a la Matritense que formara una asociación que por medio de suscripciones promoviese las escuelas de párvulos. La asociación tenía que empezar por fundar una o más escuelas en la capital que sirviesen como ejemplo y estímulo para las provincias. Se animó a que formaran parte de ella no sólo los socios de la Económica sino toda persona interesada, se hicieron llamamientos públicos y se realizó un esfuerzo de comunicación para lograr apoyos y dinero. Al final de su primer año de existencia habían logrado unir a 700 personas. En una invitación publicada por la Matritense se había otorgado gran realce al hecho de que el objeto de la nueva asociación era un asunto independiente de partidos políticos, una cuestión de buenos sentimientos en la cual todos podían colaborar fuesen las que fuesen sus opiniones en otras $\operatorname{cosas}^{222}$. Se hizo un llamamiento, sin embargo, no sólo al espíritu filantrópico del público, sino también a sus propios intereses en defensa de la armonía social ${ }^{223}$.

${ }^{221}$ Geraldine SCANDOLN, “Liberalismo y reforma social. La Sociedad para Propagar y Mejorar la Educación del Pueblo, 1838-1850", Cuadernos de Historia contemporánea, 10 (1988), pp. 23-43.

${ }^{222}$ ARSEM, leg. 341, exp. 21.

${ }^{223}$ La Gaceta de Madrid, 8 de junio de 1838, p. 3.

Attribution-NonCommercial 4.0 International (CC BY-NC 4.0). e-ISSN: 2660-552X 


\section{MODERNIZACIÓN ECONÓMICA}

Los Amigos del País siempre tuvieron como fin el fomento $y$ modernización de la economía española, siguiendo parámetros e influencias de los modelos europeos. Sus socios se integraban, voluntariamente, una vez realizado su ingreso en una de las secciones en donde podían mejor volcar sus intereses: Artes y Oficios, Industria, Agricultura... En esos años recuperaron el debate sobre el desestanco de la sala, la necesidad de adaptar la legislación para el aprovechamiento de las aguas de los ríos y arroyos que debían fecundar adecuadamente los suelos, no descuidando la repoblación del arbolado, tanto en Madrid como en los pueblos cercanos, y la creación de una biblioteca de temática agropecuaria $^{224}$. A petición de la Matritense, el gobierno estableció ocho cátedras de agricultura en diferentes provincias y encargó a sus socios todo lo concerniente al plan de enseñanzas, reglamento y vigilancia de estas ${ }^{225}$. Además, sus socios defendieron la abolición definitiva -ante las dudas de los primeros gobiernos de la regencia- de las ordenanzas gremiales y de la limpieza de sangre, conceptos ligados al Antiguo Régimen, a entender de

${ }^{224}$ Eduardo MONTAGUT CONTRERAS, "Cartilla pecuaria y bibliográfica ganadera en la sociedad Matritense en la primera mitad del XIX", Torre de los Lujanes, 58 (2006) pp. 157162. Id., "Las cartillas agrarias en la crisis del Antiguo Régimen", Torre de los Lujanes, 52 (2004) pp. 87-101.

225 Un ejemplo, la convocatoria de oposición a cátedra de agricultura de Santiago y Murcia, 9 de enero de 1835 y la de la ciudad de Toledo el 28 de marzo. La Gaceta de Madrid, no 106 y 111, de 11 de enero y 16 de abril de 1835, pp. 44 y 424.

Ihering. Cuadernos de Ciencias Jurídicas y Sociales N.․ 4 (2021)

DOI: https://doi.org/10.51743/ihering.284 
muchos de ellos ${ }^{226}$. Los Amigos del País o bien eran consultados y hacían los informes requeridos sobre algún asunto relacionado con la economía o elevaban a los responsables administrativos sus sugerencias ${ }^{227}$.

Asimismo, se organizaron concursos de premios para fomentar la creatividad, el ingenio y la modernización tecnológica, siguiendo una política ya veterana en la Sociedad. Se ofertaron premios a memorias sobre, por ejemplo, las causas de la decadencia de la agricultura viñera y olivarera, con medios para lograr su prosperidad y mejora; sobre las posibles necesidades y recursos para aumentar la agricultura madrileña; sobre el modo de establecer y generalizar en España las cajas de ahorro 228. También se ofertaron premios para el desarrollo de la industria y la calidad de la producción española, así como a la mejor memoria para el aprovechamiento de las aguas minerales de la provincia ${ }^{229}$. Estos "ensayos de beneficencia pública", como fueron definidos entonces, procuraron

${ }^{226}$ La participación de la Sociedad en la reforma y abolición de las ordenanzas gremiales ha sido minuciosamente analizada en Antonio Manuel MORAL RONCAL, Gremios $e$ Ilustración en Madrid (1775-1836), Madrid, Actas, 1998.

227 Muchos de estos informes fueron publicados por la propia Matritense, que los anunciaba en diversos medios para su venta. Así, las memorias de la institución; la representación sobre abolición de ordenanzas gremiales y limpieza de sangre de López Olavarrieta; el informe sobre ordenanzas de la hermandad de ciegos de Salustiano Olózaga; el informe sobre la ley de cerramiento de terrenos también firmada por Olózaga y el veterano informe sobre la ley agraria de Jovellanos fueron publicitados en La Gaceta de Madrid, no 468, 3 de abril de 1836, p. 4.

${ }^{228}$ Gaceta de Madrid, n 255, 9 de septiembre de 1835. El concurso y premios habían sido anunciado el 4 de marzo de 1834. Se presentaron pocas memorias y sólo una alcanzó la distinción de una medalla y el título de socio de mérito.

${ }^{229}$ Programa de premios otorgados por la Real Sociedad Económica Matritense, Gaceta de Madrid, no 235, 7 de octubre de 1834, pp. 987 y 988.

Attribution-NonCommercial 4.0 International (CC BY-NC 4.0). e-ISSN: $2660-552 X$ 
motivar a la opinión pública a participar, con sus conocimientos profesionales y prácticos, en la tarea de modernización tan deseada. Además, también desearon elevar la consideración social de agricultores, industriales y artesanos en una época donde los valores culturales todavía se encontraban en proceso de transición.

Varios socios impulsaron la creación de una cátedra de fisiología y patología de los vegetales para su aplicación a la medicina y la agricultura. Su inauguración solemne ocurrió el 11 de febrero de 1838 en el colegio de Sordomudos, al que asistieron personalidades de la vida política y científica, mostrando públicamente su apoyo ${ }^{230}$. El director de la Sociedad, el botánico Antonio Sandalio de Arias pronunció un discurso, desempeñando la cátedra Antonio Blanco Fernández, a quien, por orden de la reina María Cristina, el director del Jardín Botánico debía facilitar aquello que fuera indispensable para la docencia. Por su parte, continuó funcionando la cátedra de Economía Política, creada por la Sociedad en 1814, siendo profesor interino Eusebio María del Valle en los comienzos de la regencia. Autor de Un curso de economía política, llegó a ser director de la misma, académico de la Española y rector de la Universidad de Madrid. Para sus defensores, la ignorancia de esta disciplina dificultaba el arte del gobierno y su propagación destruiría "el germen de la revolución”. Fue, asimismo, una plataforma para la divulgación de los principios del

${ }^{230}$ Gaceta de Madrid, no 1169, 10 de febrero de 1838, p. 3.

Ihering. Cuadernos de Ciencias Jurídicas y Sociales N.ำ 4 (2021)

DOI: https://doi.org/10.51743/ihering.284 
liberalismo económico, al defender los principios de libre asociación, creación de empresas y fomento de los intereses de todas clases sociales, cortando así de raíz "los males desastrosos de la revolución" 231 .

En marzo de 1836, el gobierno de la reina dispuso que la cátedra se pusiera bajo la dependencia de la Dirección General de Estudios y que los doce mil reales de sueldo de dotación dejaran de ser abonados por el fondo de Mostrencos y pasaran a formar parte del presupuesto del Ministerio de la Gobernación, lo que supuso el reconocimiento oficial de su necesidad y calidad.

Con el respaldo de la Sociedad Económica Matritense y de otras personalidades como Ramón Mesonero Romanos, el marqués viudo de Pontejos durante ese mandato como jefe político promovió con éxito ante el Ministerio de la Gobernación la creación, junto al secular Monte de Piedad de Madrid, de una Caja de Ahorros en beneficio de "las clases menos acomodadas". Así, aprobada por el Decreto de 25 de octubre y contando con él como director-presidente de la primera Junta directiva, el 17 de febrero de 1839 esa institución crediticia popular abrió sus puertas. Más adelante se fundió con el Monte de Piedad, creación del sacerdote aragonés Francisco Piquer. La Matritense fue la cantera de donde salieron muchos de los más activos miembros de la Caja, no sólo en los primeros

231 Discurso de Eusebio del Valle, con Antonio Sandalio de Arias, subdirector de la Matritense, en la apertura del curso de la cátedra de economía política en el Real Colegio de Sordomudos. Gaceta de Madrid, no 315, 6 de noviembre de 1835, pp. 1251-1252.

Attribution-NonCommercial 4.0 International (CC BY-NC 4.0). e-ISSN: 2660-552X 
tiempos sino más adelante. De la misma manera, ostentando idéntica posición el marqués de Pontejos, el 2 de enero de 1840 inició su andadura la junta de la Sociedad filantrópica para la mejora del sistema carcelario, donde también se apuntaron socios de la Matritense para modernizar el código penal, la relación entre delito y castigo que se consideraba desproporcionada y la necesidad de reintegrar también al penado tras cumplir su condena 232 .

\section{UNA SOCIEDAD CULTURAL Y DE ENSEÑANZA A NIVEL EUROPEO}

El catedrático de derecho Juan Miguel de los Ríos en una junta de la Real Sociedad Económica Matritense, celebrada en una sala de las casas consistoriales del Ayuntamiento el 10 de octubre de 1835, propuso la fundación de un Ateneo que contribuyera a extender y consolidar "la ilustración general". Recordó los servicios que, en este sentido, había tenido la capital durante el Trienio Liberal.

Efectivamente, entre abril y mayo de 1820, tras el golpe de Riego y la restauración del sistema constitucional, un grupo de liberales había

232 Discurso leído por D. Ramón de la Sagra al terminar la sesión pública de la instalación de la Sociedad para la mejora del sistema carcelario, correccional y penal de España, 3 de enero. Gaceta de Madrid, núm. 1882, de 4 de enero de 1840, p. 3. Asimismo, ver Isabel RAMOS, "La Administración Civil Penitenciaria: militarismo y administrativismo en los orígenes del Estado de Derecho", Anuario de Historia del Derecho, LXXXII (2012), pp. 473483.

Ihering. Cuadernos de Ciencias Jurídicas y Sociales N ․․ 4 (2021)

DOI: https://doi.org/10.51743/ihering.284 
creado el Ateneo Español, sinónimo de sociedad cultural y de enseñanza, a semejanza de otros centros franceses, ingleses y belgas. Su fe radicaba en la difusión del conocimiento, como incentivo para crear el progreso de las naciones. Estuvo emparentado con agrupaciones como la Económica Matritense y con tertulias madrileñas en las que se discutían temas políticos y sociales. Tras el final del trienio y la vuelta a la plena soberanía regia, el Ateneo fue disuelto, aunque en 1832 antiguos socios, como Nicolás Arias, solicitaron al gobierno su restablecimiento. Y un año después, entre marzo y abril, el diario madrileño Correo Literario insistió en su reapertura, aprovechando los nuevos vientos políticos que se estaban desatando con la jura de la hija del rey como princesa de Asturias por las Cortes ${ }^{233}$.

En 1835, el grupo que dirigía la Real Sociedad Económica consideró interesante la propuesta de Juan Miguel de los Ríos y nombró una comisión de socios para estudiarla y organizar los pasos necesarios para reconstruirla. El sueño de un centro de instrucción que fuera también punto de reunión de minorías activas liberales y reformistas, así como una de sus plataformas ideológicas volvió a ser impulsado. Se quiso impulsar nuevas instituciones nacidas bajo un régimen que caminaba cada vez más hacia el liberalismo, frente a otras -como las Reales Academias- que muchos jóvenes consideraban llenas de venerables, pero ancianos

${ }^{233}$ Sobre la fundación de esta corporación, me remito a Víctor OLMOS, Ágora de la Libertad. Historia del Ateneo de Madrid, tomo I (1820-1923), Madrid, La esfera, 2015. 
maestros, sin incidencia en la renovación cultural que solicitaban cada vez más los intelectuales ligados a la construcción del nuevo régimen ${ }^{234}$.

Unos días más tarde, la comisión recomendó que no sólo fueran llamados a este proyecto los antiguos socios del Ateneo y de la Matritense sino también a todas aquellas personas que pudieran estar interesadas, abriendo de esa manera esta institución a un mayor número de apoyos. El 31 de octubre se reunieron más de cien socios e invitados de la Sociedad Económica para decidir finalmente si apoyaban o no el establecimiento del Ateneo. Presidió Juan Álvarez Guerra y pronto se advirtió que, entre la asistencia, había prácticamente unanimidad en cuanto al objetivo principal, pero se dividía en dos grupos en el debate sobre si debía crearse una igual a la de 1820 o una completamente nueva. Aunque no se llegó a una conclusión en este punto, por lo menos se eligió una comisión de siete personas a las que se autorizó a solicitar al gobierno el permiso necesario y diseñar las bases necesarias para ponerlo en marcha el Ateneo.

Al mes siguiente, ya estaban elaborados unos estatutos compuestos por 37 artículos del Ateneo Científico y Literario, cuyos objetivos eran el aumento de conocimientos por medio de la discusión y la

234 Rafael María de Labra, socio de la Matritense, defendió siempre las nuevas instituciones que, como el Ateneo, eran "hijas de la nueva época; con ella y por ella viven, y cuyo alto espíritu de libre discusión y absoluto respeto a todas las opiniones, viene siendo hace años uno de los primeros y más enérgicos elementos de moralización de nuestro viciado país". Así lo recoge Juan VELARDE FUERTES, "La Matritense y la cultura madrileña del siglo XIX", Torre de los Lujanes, 67 (2010) p. 93.

Ihering. Cuadernos de Ciencias Jurídicas y Sociales N.․ 4 (2021)

DOI: https://doi.org/10.51743/ihering.284 
lectura, difundiéndolos a través de la enseñanza. La entidad se dividiría en cuatro secciones: Ciencias Morales y Políticas, Ciencias Naturales, Ciencias Matemáticas y Físicas, Literatura y Bellas Artes, a las que debían adscribirse los socios. La institución establecería enseñanzas públicas y gratuitas a través de un sistema de cátedras, una biblioteca y un gabinete de física y maquinaria. Una vez cerrada la lista de socios fundadores, aquellos que quisieran ingresar lo harían mediante voto secreto, con el sistema de bolas negras y blancas. La comisión, en nombre de la Económica Matritense, elevó a la reina regente el proyecto que fue aprobado el 16 de noviembre de 1835 mediante una Real Orden ${ }^{235}$.

De esta manera, los Amigos del País, gracias a su historia de fidelidad y servicio a la Monarquía desde los tiempos de Carlos III, consiguieron lo que no pudieron los ateneístas de 1820: la protección de la Corona, que se formalizaría al aceptar la regente el título de "protectora" de la institución, así como al solicitar el infante Francisco de Paula su ingreso como socio, extensible a su hijo mayor, el infante Francisco de Asís ${ }^{236}$. Una vez autorizado el Ateneo, se convocó una junta general en la

235 Las reuniones de la Real Sociedad Económica Matritense se encuentran recogidas en el libro de actas del Ateneo de Madrid (1835-1855) que puede consultarse en la biblioteca digital del Ateneo. Cuando se inauguró el actual edificio del Ateneo en la calle del Prado el 31 de enero de 1884, Cánovas del Castillo recordó en su discurso que esta entidad era "hija de la iniciativa previsora de la Real Sociedad Económica Matritense".

${ }^{236}$ El infante Francisco de Asís aumentó su presencia en los círculos liberales durante los años treinta, como se analiza en su más reciente biografía de Antonio Manuel MORAL RONCAL, El infante Francisco de Paula Borbón, Madrid, ediciones 19, 2018. Fue elegido XVII director de la Económica Matritense entre 1818 y 1819, ver GARCÍA BROCARA, La Sociedad Económica..., p. 65.

Attribution-NonCommercial 4.0 International (CC BY-NC 4.0). e-ISSN: 2660-552X 
calle del Prado, número 28, que se convirtió en su primera sede gracias a las gestiones de Ramón de Mesonero Romanos. Fue presidida por Salustiano Olózaga, que pronto se convertiría en uno de los principales líderes del partido progresista.

Se eligió la primera junta directiva en la que participaron miembros de la Matritense como Francisco López Olavarrieta y el marqués de Ceballos, cuyo romanticismo les unía. Precisamente, sería uno de los más conocidos escritores de este movimiento cultural el primer presidente del Ateneo: Ángel de Saavedra, duque de Rivas, que insistió en la idea de que la institución era de nueva creación, cortando los hilos con la del trienio, como pensaban otros socios como Olózaga. Pero era algo propio del ambiente: los primeros ateneístas fueron, en su mayoría, liberales moderados y reformistas, que pretendieron distanciarse de los excesos cometidos durante los años 1820 a 1823. Partidarios de consolidar el régimen del Estatuto Real de 1834, no desearon nunca aventuras revolucionarias que provocaran el aumento de apoyos a los carlistas, con quienes se estaba librando una guerra decisiva. En este sentido, también se varió el nombre a "Ateneo Científico, Literario y Artístico de Madrid", el cual no volvió a ser modificado. Se reelaboraron los estatutos el 4 de enero de 1836, donde se definía al nuevo Ateneo bajo el triple carácter de academia, instituto de enseñanza y círculo literario. El primer aspirante a formar parte fue el conocido escritor Mariano José de Larra, para lo cual se 
solicitó a la Económica Matritense su caja de bolas negras y blancas para las votaciones.

Durante ese año comenzaron a inaugurarse las primeras cátedras, como la de Administración, Economía Política y Literatura española, que fueron asignadas a Cristóbal Bordiú, Eusebio María del Valle y Alberto Lista. Más tarde, se organizaron las de Hacienda y Crédito Público -que desempeñó José Antonio Ponzoa-, Literatura extranjera, Legislación dirigida por Joaquín Francisco Pacheco-, la de Geografía e Historia y la de Derecho Político Constitucional, regentada por Antonio Alcalá Galiano. Mientras, los volúmenes que formaban su biblioteca aumentaron por compras, donaciones de socios y de la propia reina María Cristina, la cual, en 1838, concedió al Ateneo un ejemplar de cada una de las obras que formaban el surtido de la Imprenta Nacional, además de una de las triplicadas que no hacían falta en la Biblioteca Nacional, en la de San Isidro y en las provenientes de otros lugares como los conventos desamortizados.

\section{UNA JUNTA DE DAMAS EN DEFENSA DE SU ESPACIO DE ACTUACIÓN SOCIAL}

A diferencia de otros centros de sociabilidad del Madrid liberal, la Económica Matritense continuó permitiendo la incorporación de mujeres a su corporación, según la tradición mantenida casi desde su fundación. Eso sí, teniendo en cuenta la concepción cultural de ambos sexos propia de la época, se organizó una sección aparte de la junta general de socios, pero con misión y jurisdicción particular, conocida como la Junta de Damas de 
Honor y Mérito. De esa manera, se visibilizaron mujeres cuya actuación social salió de su anonimato, aunque pertenecientes en su mayoría a familias de la nobleza, muchas de ellas con contactos con la servidumbre femenina que formaba parte de la camarería mayor de palacio. Esta última circunstancia resultó clave, en ocasiones, para lograr el apoyo de la familia real o de damas de la reina a determinadas actuaciones de la Junta de Damas. Por ejemplo, durante la presidencia de la duquesa de Gor, que desempeñó el cargo desde 1828 hasta 1860.

María del Carmen Chacón Carrillo de Albornoz Medrano (17701860) fue la segunda esposa de Nicolás Álvarez de Bohorques Ladrón de Guevara, primer duque de Gor, que falleció en 1805. Fue madre del segundo duque, afrancesado y liberal moderado que, si bien se le cerraron las puertas de palacio durante los periodos más absolutistas, a partir de 1832 se le abrieron, convirtiéndose en un consejero de María Cristina. Fue nombrado subdelegado de Fomento en Granada, miembro activo del Estamento de Próceres, diputado por el partido moderado y gentilhombre de cámara de la regente. Tanto la madre como su hijo destacaron como ilustrados y benefactores sociales, pero también como personas con importantes conexiones con la corte que facilitaron, por ejemplo, que se 
destinaran ciertas cantidades de dinero para la ampliación y mejora del Colegio de niñas incluseras de la $\mathrm{Paz}^{237}$.

La Junta de Damas dirigía la Escuela Lancasteriana o de enseñanza mutua para niñas, en la calle de Preciados número 2, desde el 30 de junio de 1819. En ella recibían gratuitamente la instrucción primaria por el citado sistema, unas 460 niñas. El método lancasteriano de instrucción y entrega era recursivo, ya que, si una de las alumnas aprendía la lección, era recompensada si era capaz de transmitir la información a otra compañera. Este método lo que intentaba hacer era que cada niña fuera tutora, en cierto modo, de otras. Desde junio de 1822, la tradicional dirección masculina pasó a una mujer, Ramona Aparicio, que desempeñó su puesto a satisfacción de la Junta de Damas, puesto que también lo compaginó con su papel como maestra. Los fondos con que contaba este establecimiento desde su fundación, 46.000 reales de dotación anual, aumentaron durante las siguientes décadas hasta sumar 24.000 más, bajo la continua dirección de las damas de la Matritense, las cuales nombraron una socia curadora. Ella debía vigilar el sostenimiento de la escuela, evitar vacantes y llenar los puestos ofertados, para evitar ausencias ${ }^{238}$.

Desde 1838, la Junta de Damas tuvo a su cargo la inspección del Colegio Nacional de Huérfanas de la Unión, cuya dirección ejerció su

${ }^{237}$ Antonio Manuel MORAL RONCAL, "Bases para el estudio de la nobleza en la Real Sociedad Económica Matritense", Torre de los Lujanes, 45 (2001), pp. 260-261.

238 En 1844, la curadora era María del Patrocinio Chacón y Manrique de Lara. MADOZ, Madrid..., p. 290. 
directora. Por encargo de la reina María Cristina, la duquesa de Gor fundó en Madrid la Real Asociación de Beneficencia Domiciliaria, cuyas memorias redactó, al haber escrito también las de la Inclusa y el Colegio de la Paz ${ }^{239}$. La Inclusa había sido cedida a la tutela de las Damas de la Matritense desde 1799, las cuales habían intentado que cada inclusero tuviera una dama mientras conseguían un edificio más espacioso a disposición de las monjas -Hijas de la Caridad- que ejercían allí su labor. En 1830, la duquesa viuda de Gor dirigió la elaboración de una memoria donde se reveló la permanente preocupación de las señoras por la felicidad de las criaturas condenadas a la miseria, delatando una situación siempre irresuelta.

En la primera memoria, agradeció la ayuda que la Casa Real, en materia de donaciones, siempre enviaba, pero la cifra de criaturas fallecidas -sobre todo en su primer año de vida- resultaba preocupante. Las dificultades económicas eran grandes, pues no llegaba suficiente dinero de unas rentas eclesiásticas y se habían tenido que alquilar cuartos destinados inicialmente a personal docente, del cual se había tenido que prescindir. La duquesa, propuso una nueva norma que fue aprobada por la Junta de Damas, consistente en nombrar socias para los pueblos donde había expósitos, "para vigilar el trato que dan las nodrizas a los niños, por ser más propio del sexo" con la colaboración del párroco en la elección de las que

\footnotetext{
${ }^{239}$ Vizconde de SAN ALBERTO, Los directores de la Real Sociedad Económica Matritense de Amigos del País y las presidentas de su Junta de Damas de Honor y Mérito, Madrid, Real Sociedad Económica Matritense de Amigos del País, 1925, p. 57.
}

Ihering. Cuadernos de Ciencias Jurídicas y Sociales N ․ㅡ 4 (2021)

DOI: https://doi.org/10.51743/ihering.284 
considere más cristianas y de buenas cualidades. En todos aquellos trabajos, misiones, tareas, en los que se valoraba la participación de las mujeres, se tenía en cuenta la razón del sexo. La condesa de la Vega del Pozo y Simona Calzada de Embite fueron las encargadas del partido de Guadalajara y de la ciudad de Alcalá de Henares. Finalmente, añadió un informe sobre los legados y limosnas destinadas a la Inclusa de alhajas, ropas, zapatos, muebles, etc., provenientes de cesiones particulares. Tras su lectura, resultaba evidente que era necesario dotar a la institución de una mayor ayuda económica. En 1836, doce damas se ofrecieron para vigilar el cuidado que realizaban las nodrizas contratadas por la Inclusa con los niños, repartiéndose los barrios de Madrid entre ellas ${ }^{240}$.

A partir de ese año, la Junta Municipal de Beneficencia reclamó a las damas informes de las asignaciones que recibía la Inclusa. Cada una de las personas que formaba dicha comisión arguyó que necesitaba toda la información posible para poder evaluar y vigilar esta clase de instituciones. Se produjo una avalancha de peticiones de todo tipo de datos; necesitaban conocer el funcionamiento, las normas, el reglamento de la Inclusa. Todo lo concerniente a personal, nodrizas, niños: cuántos había en el centro, sus edades, cuántos se criaban fuera, cuál era la actividad de las monjas, su trabajo y atribuciones. $Y$ con qué fuentes de ingresos se mantenían y con qué fondos contaban en ese momento. En un principio todo ello fue motivo

${ }^{240}$ Carmen MACEIRAS REY, Las niñas abandonadas: Ia Inclusa de Madrid y el Colegio de la Paz, (1807-1934), tesis doctoral, Universidad Complutense de Madrid, 2017, pp. 72-81.

Attribution-NonCommercial 4.0 International (CC BY-NC 4.0). e-ISSN: 2660-552X 
de controversia, pues se puso en cuestión las atribuciones de cada parte. Hasta entonces toda la responsabilidad y reglas habían sido asumidas por las damas de la Matritense. Pese a las limitaciones económicas, ellas tenían el poder, eran las que, por Orden Real, desde principios del siglo, decidían en todo lo concerniente a la dirección y administración de la Inclusa y el Colegio de la Paz; ellas disponían y tomaban decisiones sobre la vida y futuro de miles de criaturas. Las señoras se vieron en la obligación de enfrentarse a un trabajo inmenso para responder a todos los cuestionarios que les enviaron y realizar copias escritas a mano de todos los documentos. Pero, por lo menos, la Junta confirmó la indudable utilidad de la Inclusa y del Colegio.

En 1838, la Junta de Damas elaboró un informe como respuesta a las preguntas del marqués de Valgornera, nombrado inspector de los establecimientos de beneficencia de Madrid. La dama Simona Calzada y Embite se hizo responsable del informe sobre las nodrizas, por ser ella la que recibía los partes diarios. La condesa de la Vega del Pozo informó de todo lo relacionado con los trabajos de las hermanas de la Caridad. La comisión de la Junta de Beneficencia trató de investigar el servicio que prestaban las monjas y su utilidad, dentro del espíritu anticlerical y desamortizador de aquellos años. La condesa de Atarés informó al comisionado de todo lo relativo al funcionamiento del Colegio de niñas incluseras de la Paz. El mismo puso en evidencia el contraste con la información desprendida de cartas, denuncias, oficios y reclamaciones de 
pagas. Por un lado, se encontraba el ideal al que aspiraban las damas reflejado en el papel -como consecuencia en la versión oficial del funcionamiento del establecimiento- y por el otro, la realidad, dura e implacable vivida por las mujeres y criaturas que diariamente tenían que afrontarla en el interior, una vez atravesaban sus puertas.

Las monjas tenían como misión lograr mantener la armonía y paz, no solo con las niñas sino con las nodrizas, lo que suponía, según la condesa de Atarés, un gran mérito, teniendo en cuenta la facilidad con la que se alteraba el orden entre cualquier grupo numeroso de gente que había de convivir durante todo el día. Por otra parte, debido al bajo nivel de instrucción y educación de estas mujeres, con frecuencia surgían las disputas entre ellas a pesar de la vigilancia de las hermanas. Las monjas llevaban la economía de la Casa y tenían la llave de la despensa. Expresó toda clase de alabanzas por lo admirable de su administración y el "cortísimo estipendio" con que afrontaban la alimentación de tantas personas. Se ocupaban del cuidado y limpieza de la iglesia, del jabonado de las niñas, del lavado diario de entre 800 a 1.000 pañales, aparte de todo el resto de ropas. Dos monjas velaban todas las noches cuidando de los niños que lloraran y los llevaban a la cama con su nodriza respectiva; cuidaban a las amas si enfermaban, así como a las criaturas, de las cuales también se encargaban del tiempo de su destete. Las hermanas habían encontrado una solución para ofrecer a esos niños algo de afecto y aliviar su malestar. Como subrayó la condesa de Atarés, cada una tomaba a uno en sus brazos 
o de la mano y lo llevaba por la casa mientras se ocupaba de sus faenas. Sin embargo, no ocultó que necesitaban un edificio más grande, pues la falta de ventilación y de personal también incidía en la mortalidad.

De esta manera, mientras los socios de la Matritense impulsaron la modernización de la ciudad de Madrid, dentro de los parámetros liberales y románticos de la época, las damas de su Junta de Honor y Mérito no sólo participaron en las clásicas tareas de beneficencia, sino que procuraron mantener, pese a los avatares de la época, algunas instituciones para niñas huérfanas donde pudieran aprender algún oficio, evitando su degeneración social en la pobreza y la marginación. Fueron los primeros pasos de la organización de un sistema de beneficencia por parte del Estado liberal, que se apoyó en asociaciones privadas como la Junta de Damas, más personal y directa, más selectiva y proselitista ${ }^{241}$. La evidencia de que existían familias en situación económica y social peor, a las cuales había que apartar del camino de la degradación, del vicio, del pecado y del odio debió de influir en su manera para movilizar a estas mujeres. Ellas se consideraron importantes constructoras de una armonía general,

\footnotetext{
${ }^{241}$ En 1840, por disposición de la Junta provisional de Gobierno, volvieron a quedar estos establecimientos bajo la inspección de la Corporación y Junta municipal de Beneficencia, cesando, por acuerdo de ésta, la Junta de Damas de Honor y Mérito, que volvió a ejercer su misión, a ruegos del jefe político de la provincia, en 1850. Sobre el colegio de la Paz, ver Florentina VIDAL y Benicia VIDAL, "El colegio de nuestra señora de la Paz para niñas " expuestas " de Madrid", Anales del Instituto de Estudios Madrileños, 30 (1991), pp. 191210.
}

Ihering. Cuadernos de Ciencias Jurídicas y Sociales N.ำ 4 (2021)

DOI: https://doi.org/10.51743/ihering.284 
amenazada por el aumento de diferencias sociales, como la lenta proletarización del artesanado.

\section{BIBLIOGRAFÍA}

Antonio Manuel MORAL RONCAL y Ricardo COLMENERO MARTíNEZ, “Un espacio reformista en el Madrid de Fernando VII: la Real Sociedad Económica Matritense de Amigos del País (1814-1833)", Madrid: Revista de arte, geografía e historia, 8 (2006) pp. 87-127

Archivo de la Real Sociedad Económica Matritense (ARSEM), Libro de Actas $\mathrm{A} / 110 / 45$. Sobre instalación y nombramiento de diputaciones permanentes en la Villa y Corte, ver leg. 314, exp. 3 y leg. 320, exp. 9.

Real Orden de 9 de abril de 1835 publicada en La Gaceta de Madrid, no 124, 4 de mayo de 1835, p. 1.

José Luis GARCÍA BROCARA, La Sociedad Económica Matritense de Amigos del País. Páginas de una gloriosa historia, Madrid, Artes gráficas Reyes, 1976, p. 69.

VIVES, J. L., "El corregidor marqués viudo de Pontejos", Torre de los Lujanes, 20 (1992), pp. 121-127

SALVADOR PRIETO, María del Socorro, "Precisiones sobre la erección de las estatuas del padre Piquer y el marqués de Pontejos en Madrid", Archivo español de Arte, 62 no 247 (1989) pp. 360-363.

Attribution-NonCommercial 4.0 International (CC BY-NC 4.0). 
Joaquín MARTíN MUÑOZ, "La gestión del marqués viudo de Pontejos en el Ayuntamiento de Madrid" en Luis E. OTERO y Ángel Bahamonde (eds.), Madrid en el siglo XIX, Madrid, Comunidad de Madrid, 1986, pp. 193209

Joaquín MARTÍN MUÑOZ, "La gestión del marqués viudo de Pontejos en el Ayuntamiento de Madrid" en Luis E. OTERO y Ángel Bahamonde (eds.), La política local en el Madrid de Pontejos (1834-1836), Madrid, Caja de Madrid, 1995.

Luis PERDICES, "Valle, Eusebio María del”, en Luis PERDICES y John REEDER (eds.), Diccionario de pensamiento económico en España 1500-2000, Madrid, Síntesis-ICO, 2003, p. 412.

Carlos GONZÁLEZ ECHEGARAY, "Reseña histórica de los emblemas de la Sociedad Matritense", Torre de los Lujanes, 31 (1996) pp. 257-258

La Gaceta de Madrid, no 235, 7 de octubre de 1834, pp. 987 a 988.

José Luis GARCÍA BROCARA, "La reinstalación de la escuela de taquigrafía en el Instituto de San Isidro", Torre de los Lujanes, 24 (1993) pp. 189197.

Eduardo MONTAGUT CONTRERAS, "La creación de la imprenta del Colegio de Sordomudos de Madrid", Torre de los Lujanes, 27 (1994), pp. 273288

La Gaceta de Madrid, ㅇ 260, 14 de septiembre de 1835, p. 1036

Ihering. Cuadernos de Ciencias Jurídicas y Sociales N.․ 4 (2021)

DOI: https://doi.org/10.51743/ihering.284 
Antonio CABALLERO GARCÍA, "Desamortización y patrimonio documental: un ejemplo de tratamiento de archivos en el siglo XIX", Signo. Revista de Historia de la Cultura Escrita, 15 (2005) pp. 77-117

María del Val GONZÁLEZ DE LA PEÑA, "La enseñanza de la paleografía en España. Los orígenes y las primeras cátedras", en Joaquín GÓMEZ PANTOJA, Excavando papeles. Indagaciones arqueológicas en los archivos españoles, Guadalajara, Aaché Ediciones, 2004, pp. 43-71.

La Gaceta de Madrid, 14 de febrero de 1840, p. 4.

Pascual MADOZ, Madrid. Audiencia, provincia, intendencia, vicaría, partido y villa (1848). Reedición, Madrid: Ediciones Giner, 1981, p. 307.

Geraldine SCANDOLN, "Liberalismo y reforma social. La Sociedad para Propagar y Mejorar la Educación del Pueblo, 1838-1850", Cuadernos de Historia contemporánea, 10 (1988), pp. 23-43.

La Gaceta de Madrid, 8 de junio de 1838, p. 3.

Eduardo MONTAGUT CONTRERAS, "Cartilla pecuaria y bibliográfica ganadera en la sociedad Matritense en la primera mitad del XIX", Torre de los Lujanes, 58 (2006) pp. 157-162

Eduardo MONTAGUT CONTRERAS, "Las cartillas agrarias en la crisis del Antiguo Régimen", Torre de los Lujanes, 52 (2004) pp. 87-101.

Antonio Manuel MORAL RONCAL, Gremios e Ilustración en Madrid (17751836), Madrid, Actas, 1998. 
Gaceta de Madrid, no 255, 9 de septiembre de 1835.

Gaceta de Madrid, no 1169, 10 de febrero de 1838, p. 3.

Isabel RAMOS, "La Administración Civil Penitenciaria: militarismo y administrativismo en los orígenes del Estado de Derecho", Anuario de Historia del Derecho, LXXXII (2012), pp. 473-483.

Víctor OLMOS, Ágora de la Libertad. Historia del Ateneo de Madrid, tomo I (1820-1923), Madrid, La esfera, 2015.

Juan VELARDE FUERTES, "La Matritense y la cultura madrileña del siglo XIX", Torre de los Lujanes, 67 (2010) p. 93.

Antonio Manuel MORAL RONCAL, El infante Francisco de Paula Borbón, Madrid, ediciones 19, 2018.

Antonio Manuel MORAL RONCAL, "Bases para el estudio de la nobleza en la Real Sociedad Económica Matritense", Torre de los Lujanes, 45 (2001), pp. 260-261.

Vizconde de SAN ALBERTO, Los directores de la Real Sociedad Económica Matritense de Amigos del País y las presidentas de su Junta de Damas de Honor y Mérito, Madrid, Real Sociedad Económica Matritense de Amigos del País, 1925, p. 57.

Carmen MACEIRAS REY, Las niñas abandonadas: la Inclusa de Madrid y el Colegio de la Paz, (1807-1934), tesis doctoral, Universidad Complutense de Madrid, 2017, pp. 72-81. 
Florentina VIDAL y Benicia VIDAL, "El colegio de nuestra señora de la Paz para niñas " expuestas " de Madrid", Anales del Instituto de Estudios Madrileños, 30 (1991), pp. 191-210. 